\title{
Beneficial Effects of Citrus Juice Fermented with Lactobacillus plantarum YIT 0132 on Japanese Cedar Pollinosis
}

\author{
Naomi HARIMA-MIZUSAWA ${ }^{1 *}$, Tohru IINO ${ }^{1}$, Norie ONODERA-MASUOKA ${ }^{1}$, Noriko KATO-NAGAOKA ${ }^{1}$, \\ Junko KIYOSHIMA-SHIBATA ${ }^{1}$, Atsushi GOMI ${ }^{1}$, Harue SHIBAHARA-SONE${ }^{1}$, Mitsuyoshi KANO ${ }^{1}$, \\ Kan SHIDA ${ }^{1}$, Masashi SAKAI ${ }^{1}$, Kouji MIYAZAKI ${ }^{1}$ and Fumiyasu ISHIKAWA ${ }^{1}$ \\ ${ }^{1}$ Yakult Central Institute for Microbiological Research, 1796 Yaho, Kunitachi-shi, Tokyo 186-8650, Japan
}

Received April 2, 2014; Accepted June 11, 2014; Published online in J-STAGE July 25, 2014

Recently, the prevalence of allergies in Japan has been increasing. Certain types of fruit juice and lactic acid bacteria are known to alleviate allergic symptoms. Therefore, we examined whether citrus juice fermented by a specific lactic acid bacteria can improve the symptoms of Japanese cedar pollinosis (JCPsis). Lactobacillus plantarum YIT 0132 (LP0132) was selected based on its high proliferative activity in citrus juice and anti-inflammatory interleukin-10inducing activity. Dietary administration of heat-killed LP0132 cells or citrus juice fermented with LP0132 was found to significantly suppress nasal rubbing in a JCPsis mouse model, indicating relief of allergy symptoms. To evaluate the effects of LP0132-fermented citrus juice on pollinosis symptoms and quality of life (QOL) in humans with JCPsis, a single-blind, placebo-controlled, parallel-group clinical trial was conducted. The participants were 42 adults with JCPsis. They ingested $100 \mathrm{~mL}$ of sterilized LP0132-fermented citrus juice (active group) or unfermented citrus juice (placebo group) once daily for 8 weeks. Immediately after the pollen peak when allergy symptoms and QOL loss were most severe, itchy eyes, itchy skin, and QOL loss by JCPsis were alleviated in the active group compared with the placebo group. At 10 weeks after starting the intervention, increased the levels of blood eosinophils were significantly suppressed in the active group compared with the placebo group. We conclude that continuous ingestion of citrus juice fermented with LP0132 may help alleviate the allergy symptoms and impaired QOL caused by JCPsis.

Key words: Lactobacillus plantarum, citrus juice, interleukin-10, Japanese cedar pollinosis, mouse model, clinical trial, eosinophils

\section{INTRODUCTION}

Japanese cedar pollinosis (JCPsis) is an allergic reaction to the pollen of the Japanese cedar (Cryptomeria japonica) and is the most common type of allergic rhinitis in Japan. Individuals with pollinosis experience sneezing, runny nose, blocked nose, and itchy eyes every spring. Those with severe symptoms frequently develop asthma or bronchitis as complications. According to epidemiological studies, the number of people in Japan with JCPsis was estimated to be about 30 million (26.5\%

\footnotetext{
*Corresponding author. Mailing address: Naomi Harima-Mizusawa, Yakult Central Institute for Microbiological Research, 1796 Yaho, Kunitachi-shi, Tokyo 186-8650, Japan. Phone: +81-42577-8960, Fax: +81-42-577-3020. E-mail: naomi-mizusawa@ yakult.co.jp (C)2014 BMFH Press

This is an open-access article distributed under the terms of the Creative Commons Attribution Non-Commercial No Derivatives (bync-nd) License $<$ http://creativecommons.org/licenses/by-nc-nd/3.0/>.
}

of the Japanese population) in 2008 [1]. JCPsis has therefore been called the national disease of Japan. JCPsis reduces quality of life (QOL), and the cost of treatment with antihistamines, steroids, and other drugs is high. Furthermore, long-term administration of these drugs frequently causes side effects. Thus, ways to prevent or treat pollen allergies without drugs are urgently required.

The hygiene hypothesis states that the lack of exposure to infectious agents, symbiotic microorganisms, or parasites in early childhood increases susceptibility to allergic diseases [2]. According to this theory, the immunomodulatory effects of microbial contact in the intestine are important. By this reasoning, the involvement of lactic acid bacteria (LAB) in allergic diseases has recently received considerable interest. In fact, many clinical trials have been conducted to examine the effects of LAB on allergic diseases, and evidence for the health benefits of fermented milk and bacterial cells with respect to JCPsis has been accumulating [3-9]. $\mathrm{LAB}$ with anti-allergy effects often induce the release of 
cytokines from immunocytes. For example, a strain of Lactobacillus pentosus has been reported to be a highly potent interleukin (IL)-10 inducer that produces an antiallergic effect in vivo [10].

Some types of herbs and natural herbal products have been demonstrated to have anti-allergic potential. An example of this is hesperidin, a flavanone glycoside found abundantly in citrus fruits and known for beneficial effects such as anti-inflammatory activity, inhibition of degranulation of mast cells, relief of edema, and prevention of anaphylaxis [11-13]. In this study, we selected a strain of LAB showing both high proliferative activity in citrus juice and anti-allergic activity in an animal experiment, and conducted a clinical trial to examine the beneficial effects of citrus juice fermented with the selected LAB on allergy symptoms in individuals with JCPsis.

\section{MATERIALS AND METHODS}

\section{Bacterial culture}

About 100 strains of LAB isolated from various traditional fermented foods or the environment were obtained from the culture collection of Yakult Central Institute for Microbiological Research (YIT; Tokyo, Japan).

\section{Proliferative activity in citrus juice}

LAB were pre-cultured in Lactobacilli MRS Broth (Difco $^{\mathrm{TM}}$, Becton Dickinson and Company, Detroit, MI, USA) at $37^{\circ} \mathrm{C}$ for $16 \mathrm{hr}$. Then, $40 \mu \mathrm{L}$ of the pre-culture containing almost $4 \times 10^{5}$ viable cells was inoculated into $10 \mathrm{~mL}$ of $100 \%$ reconstituted citrus juice (Yakult Honsha Co., Ltd., Tokyo, Japan) and incubated at $37^{\circ} \mathrm{C}$ for 48 $\mathrm{hr}$. Viable cells were counted by the agar plate method using Lactobacilli MRS Broth and expressed in colonyforming units $(\mathrm{CFU}) / \mathrm{ml}$.

\section{Heat-killed LAB cells}

LAB were cultured at $37^{\circ} \mathrm{C}$ for $48 \mathrm{hr}$ in Lactobacilli MRS Broth, washed with sterilized water, killed by heating at $100^{\circ} \mathrm{C}$ for $30 \mathrm{~min}$ and then lyophilized to prepare a powder of heat-killed cells.

\section{IL-10- and IL-12-inducing activities of LAB in peritoneal macrophage culture}

IL-10- and IL-12-inducing activities of LAB in peritoneal macrophages were evaluated according to a previously reported method [14]. Briefly, peritoneal macrophages were prepared from female BALB/c mice (8-12 weeks old, Japan SLC, Shizuoka, Japan) 4 days after intraperitoneal injection of $4 \%$ thioglycollate broth

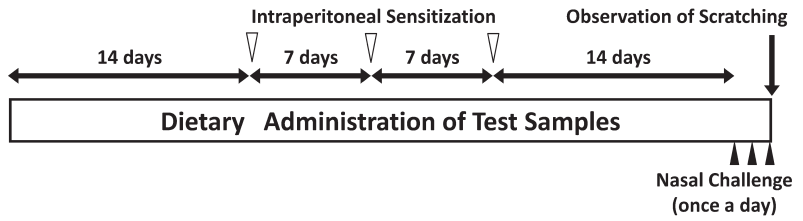

Fig. 1. Protocol for the animal experiment to evaluate anti-allergic effect of fermented citrus juice.

(Difco $^{\mathrm{TM}}$, Becton Dickinson and Company, Detroit, MI, USA). Mouse peritoneal macrophages $\left(2 \times 10^{5}\right.$ cells $/ 200 \mu \mathrm{L} /$ well) were incubated at $37^{\circ} \mathrm{C}$ for $24 \mathrm{hr}$ in RPMI\#1640 medium $\left(\right.$ Gibco $^{\circledR}$, Life Technologies, Carlsbad, CA, USA) containing $10 \%$ fetal calf serum together with heat-killed LAB cells $(10 \mu \mathrm{g} / \mathrm{ml})$. The concentrations of IL-10 and IL-12p70 in the coculture supernatant were determined by enzyme-linked immunosorbent assay according to the method of Kaji et al [15].

\section{LP0132-fermented citrus juice}

Valencia orange juice (Cutrale Co., Ltd., Araraquara, Brazil) was fermented with LP0132 at $37^{\circ} \mathrm{C}$ for $48 \mathrm{hr}$. This LP0132-fermented citrus juice was lyophilized for the animal experiment or sterilized for the clinical trial by heating at $90^{\circ} \mathrm{C}$ for $5 \mathrm{~min}$. The sterilized LP0132fermented citrus juice was found to contain LP0132 cells at a concentration of approximately $8 \times 10^{10}$ cells $/ 100 \mathrm{~mL}$ using the DAPI counting method [16].

\section{Anti-allergic effect in JCPsis mouse model}

Anti-allergy effects were examined in a JCPsis mouse model according to the method of Yamamoto et al [17]. The experimental protocol is shown in Fig. 1. Female B6D2F1 mice (4 weeks old) were purchased from Charles River Laboratories Japan (Kanagawa, Japan) and fed a commercial non-purified diet (Oriental MF; Oriental Yeast Co., Ltd., Tokyo, Japan) during the habituation period for 1 week. Then the mice were assigned to 6 groups (blank, control, anti-histamine, unfermented juice, fermented juice, and killed cells) so that average body weight was similar between the groups. Mice were housed ( 4 mice per cage) in an air-conditioned room (at $25 \pm 1{ }^{\circ} \mathrm{C}$, with 12 -hr light-dark cycle: lights on from 08:30 to 20:30, humidity $60 \pm 5 \%$ ) with access to food and water ad libitum. Mice in the blank, control, and anti-histamine groups were fed a basal diet (AIN-76 containing $50 \mathrm{~g}$ sucrose/100 g; Oriental Yeast Co., Ltd), and those in the unfermented juice, fermented juice, and killed cells groups were fed a test diet for 45 days. The test diet for the unfermented and 
Table 1. Treatment conditions for the animal experiment to evaluate anti-allergy effects of fermented citrus juice

\begin{tabular}{|c|c|c|c|c|}
\hline Group & Sensitization a) & Nasal injection & Loratadine administration $\mathrm{d}$ ) & Number of mice \\
\hline Blank & Done & Saline ${ }^{b)}$ & Not done & 4 \\
\hline Control & Done & JCP extract $\left.{ }^{c}\right)$ & Not done & 12 \\
\hline Anti-histamine & Done & JCP extract ${ }^{c)}$ & Done & 8 \\
\hline Unfermented juice & Done & $\mathrm{JCP}$ extract $\mathrm{c})$ & Not done & 12 \\
\hline Fermented juice & Done & JCP extract $\left.{ }^{c}\right)$ & Not done & 12 \\
\hline Killed cells & Done & JCP extract ${ }^{c)}$ & Not done & 8 \\
\hline
\end{tabular}

fermented juice groups was prepared by replacing $3.75 \mathrm{~g}$ of sucrose in $100 \mathrm{~g}$ of AIN-76 diet with the same amount of the lyophilized powder of raw Valencia orange juice or LP0132-fermented citrus juice, respectively. The diet for the fermented juice group contained approximately $5.3 \times 10^{8} \mathrm{CFU} / \mathrm{kg}$ of LP0132. The test diet for the killed cells group was prepared by mixing an AIN-76 diet with the heat-killed LP0132 cells at a concentration of $0.3 \mathrm{mg}$ powder/g, corresponding to about $6.6 \times 10^{8}$ cells $/ g$, before heat killing.

As shown in Fig. 1 and Table 1, all mice were sensitized once a week for 3 weeks by intraperitoneal injection of $10 \mu \mathrm{g}$ of Japanese cedar pollen (JCP) extract-Cj (LsL Co., Ltd., Osaka, Japan) with $2.0 \mathrm{mg}$ of alum adjuvant (SigmaAldrich, St. Louis, MO, USA). Two weeks after the third sensitization, all mice except those in the blank group were intranasally challenged with $10 \mu \mathrm{L}$ of $0.1 \%$ solution of JCP extract; those in the blank group were injected with the equivalent amount of saline. The intranasal challenge (both nasal cavities) was performed once daily for 3 consecutive days, and the number of nasal rubbing events during 10 min was counted immediately after the last challenge. In the anti-histamine group, loratadine (Claritin $^{\mathrm{TM}}$; Merck \& Co., Inc., Whitehouse Station, NJ, USA), a second-generation $\mathrm{H}_{1}$ histamine antagonist drug, was administered at a dose of $0.2 \mathrm{mg} /$ mouse $1 \mathrm{hr}$ before each challenge.

All animal experiments were conducted in accordance with the guidelines of the Animal Studies Committee of Yakult Central Institute for Microbiological Research (Tokyo, Japan).

\section{Clinical trial}

The participants enrolled in the clinical trial were 42 adults with JCPsis (average age, 38.2 \pm 10.2 years) living in or near Tachikawa City, Tokyo, Japan. The exclusion criteria were food allergy, pregnant or lactating, and planning to become pregnant. Prior to enrollment, the purpose and protocol of the trial were fully explained to all the participants, after which signed informed consent was obtained. Throughout the test period, intake of beverages containing LAB or bifidobacteria; food containing LAB such as kimchi, cheese, and pickles; all citrus fruits except for grapefruit; and foods with antipollinosis potential were restricted. The use of eye drops, nose drops, and anti-pollinosis drugs and hospital visits were not restricted but were recorded in a diary. The protocol was approved by the Human Studies Committee of Yakult Central Institute for Microbiological Research (Tokyo, Japan), in accordance with the Declaration of Helsinki and the Committee's own guidelines.

A single-blind, placebo-controlled, parallel-group trial was conducted in the spring of 2010. Participants were divided into a placebo group and an active group according to a completely randomized design, so that there would be no bias in terms of age, sex ratio, body mass index, symptom score of pollen-induced disease during the last pollen season and pre-observation period, co-medications, and number of hospital visits. Once daily after lunch for 8 weeks, participants in the active group ingested $100 \mathrm{~mL}$ of the sterilized LP0132-fermented citrus juice, and those in the placebo group consumed the equivalent amount of Valencia orange juice flavored to taste the same as the drink for the active group.

Throughout the 12-week test period (2 weeks preobservation, 8 weeks sample intake, and 2 weeks postobservation), questionnaires were completed to assess symptoms of pollinosis (runny nose, sneezing, blocked nose, itchy nose, itchy eyes, and watery eyes) and QOL loss, in accordance with the Japan Rhinoconjunctivitis Quality of Life Questionnaire [18]. The degree of skin itchiness was evaluated using a similar questionnaire about symptoms of pollinosis. Blood samples were collected from a brachial vein just before completing the 


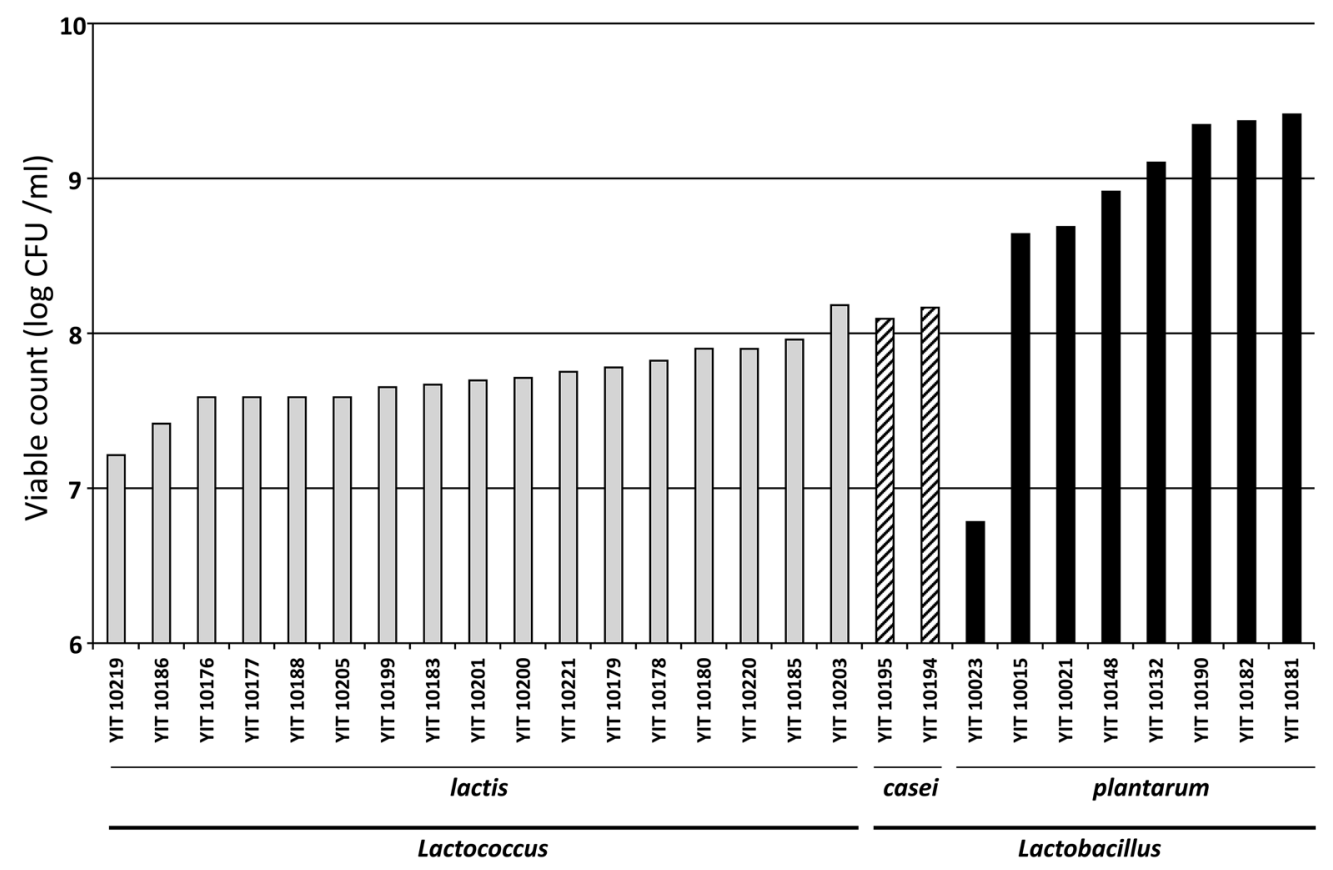

Fig. 2. Proliferative activity of lactic acid bacteria in citrus juice.

questionnaire and at 4 and 8 weeks after initiation of sample intake. The serum concentrations of immunoglobulin E (IgE) (total, specific for JCP, and specific for Japanese cypress pollen) were determined by fluorescent enzyme immunoassay. Blood eosinophil counts were determined by flow cytometry using an auto-analyzer (Sysmex XE2100, Sysmex Co., Ltd., Hyogo, Japan).

\section{Statistical analysis}

In the animal experiment, data were compared between the groups by Tukey's test. In the clinical trial, questionnaire data were compared between the groups by Wilcoxon's rank-sum test, and blood data were compared between the groups by Welch's t-test. All statistical analyses were performed using the SAS Preclinical Package software for Windows (ver. 5.0, SAS Institute Japan Ltd., Tokyo, Japan). Two-sided p-values less than 0.05 were considered statistically significant.

\section{RESULTS}

Primary screening of $L A B$ with high proliferative activity in citrus juice

The proliferative activities in citrus juice of about 100 LAB strains were compared. Figure 2 shows the results of 29 representative strains tested. Most Lactobacillus plantarum strains showed good proliferative activity, which was defined as more than $2 \times 10^{8} \mathrm{CFU} / \mathrm{ml}$ after 48 $\mathrm{hr}$ of culture in citrus juice, in contrast to Lactococcus lactis and Lactobacillus casei strains. Seven strains of $L$. plantarum (YIT 0132, YIT 0148, YIT 10015, YIT 10021, YIT 0181, YIT 0182, and YIT 0190) were selected for secondary screening.

Secondary screening of LAB with IL-10- and IL-12inducing activities

Table 2 shows the IL-10- and IL-12-inducing activities of heat-killed cells of LAB. All strains potently induced the production of both IL-12 and IL-10. Finally, LP0132 was selected on the basis of it having high IL-10-inducing activity and the highest ratio of IL-10/IL-12.

\section{Anti-allergic effects of LP0132 in JCPsis mouse model}

Figure 3 shows the number of nasal rubbing events after intranasal challenge in the mouse model of JCPsis. The number was significantly higher $(p<0.001)$ in the control group than in the blank group that received the same amount of saline instead of intranasal challenge. Significant reductions in nasal rubbing were observed in both the fermented juice and killed cells groups compared with the control group, and these effects were comparable to those of the anti-histamine group $(p<0.001)$. The unfermented juice group had a tendency toward a reduction in nasal rubbing $(\mathrm{p}=0.089)$ compared 
Table 2. Interleukin (IL)-10- and IL-12-inducing activities of the heat-killed cell powders of $L$. plantarum strains in mouse intraperitoneal macrophage culture

\begin{tabular}{llrc}
\hline \multicolumn{1}{c}{ Strain } & \multicolumn{1}{c}{$\begin{array}{c}\text { IL-10 } \\
(\mathrm{ng} / \mathrm{ml})\end{array}$} & \multicolumn{1}{c}{$\begin{array}{c}\text { IL-12p70 } \\
(\mathrm{ng} / \mathrm{ml})\end{array}$} & IL-10/IL-12 ratio \\
\hline YIT 0132 & $2.54 \pm 0.28^{\mathrm{a})}$ & $7.92 \pm 0.93$ & $0.321 \pm 0.024$ \\
YIT 0148 & $2.20 \pm 0.28$ & $9.98 \pm 2.22$ & $0.225 \pm 0.031$ \\
YIT 10015 & $1.02 \pm 0.12$ & $12.09 \pm 2.04$ & $0.086 \pm 0.019$ \\
YIT 10021 & $1.75 \pm 0.26$ & $18.33 \pm 1.93$ & $0.095 \pm 0.004$ \\
YIT 10181 & $1.35 \pm 0.16$ & $19.30 \pm 0.75$ & $0.070 \pm 0.006$ \\
YIT 10182 & $2.10 \pm 0.10$ & $8.86 \pm 0.61$ & $0.238 \pm 0.008$ \\
YIT 10190 & $1.90 \pm 0.02$ & $9.78 \pm 0.88$ & $0.195 \pm 0.016$ \\
Medium only & $0.56 \pm 0.11$ & $0.19 \pm 0.13$ & - \\
\hline
\end{tabular}

a) Values are expressed as the mean $\pm \mathrm{SD}$.

with the control group. No differences in body weight gain or food consumption were observed between the experimental groups.

\section{Anti-allergic effects of sterilized LP0132-fermented citrus juice in individuals with JCPsis}

With respect to the symptoms of pollinosis, the total score of all questionnaire items fluctuated over time, showing a pattern corresponding to the dispersion of JCP in Tachikawa City (Fig. 4). In other words, there was a peak in JCP dispersion in Tachikawa City on March 11, and the highest scores for each questionnaire item were observed on March 15 (5 weeks after initiation of sample intake).

Figure 5A shows the average scores of questionnaire items when symptoms were worst. Most of the scores except for runny nose were lower in the active group than in the placebo group. The average score for itchy eyes in the active group was significantly lower $(\mathrm{p}<0.05)$ than that in the placebo group. With regard to QOL loss, each score for the 17 questionnaire items was highest on March 15 (data not shown). As shown in Fig. 5B, all QOL loss scores were lower in the active group than in the placebo group. In the active group, the scores for "deterioration of memory" ( $p<0.05)$, "nervous in the company of others" $(p<0.05)$, and "indisposed" $(p<0.05)$ were significantly lower, and that for "decline in cognitive power" showed a weaker tendency toward a reduction compared with the placebo group ( $\mathrm{p}=0.094)$.

Figure $6 \mathrm{~A}$ to $\mathrm{C}$ shows the time-dependent changes in the total scores of all questionnaire items for pollinosis symptoms, scores for itching of skin, and the average score for itching (skin, eyes, and nose), respectively. As shown in Fig. 6A, the total scores for all questionnaire items were highest a few days after the peak in JCP dispersion. As for nasal and eye symptoms, both scores

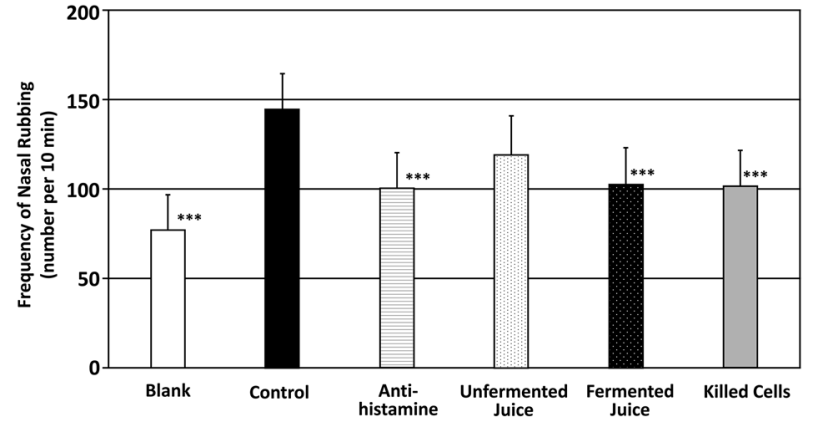

Fig. 3. Effect of Lactobacillus plantarum YIT 0132 on the allergenic reaction after intranasal challenge in the mouse model of Japanese cedar pollinosis. Numbers of nasal rubbing events after intranasal challenge are expressed as the mean \pm standard deviation. ${ }^{* * *} \mathrm{p}<0.001$ versus the control group.

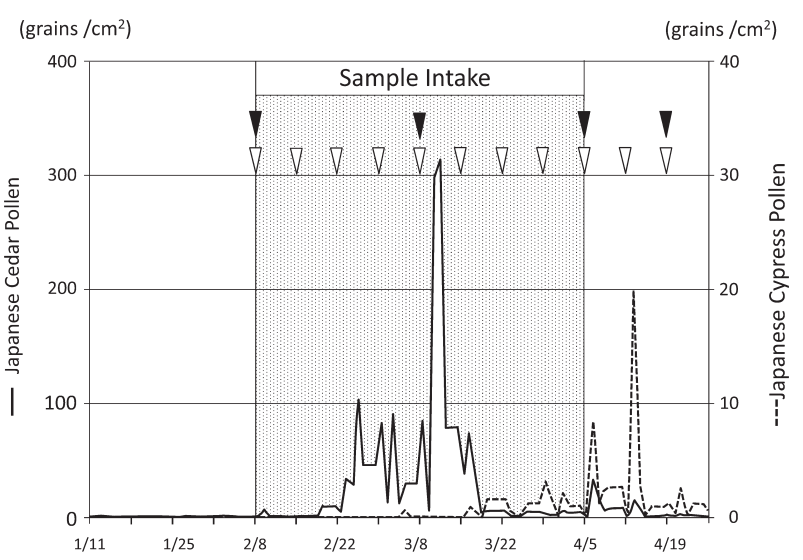

Fig. 4. Pollen dispersion in Tachikawa City in the spring of 2010 and the clinical trial schedule. The test samples were ingested from February 8 to April 5 (light gray). The questionnaires regarding pollen disease symptoms and quality of life were completed at 1-week intervals (white arrowheads), and blood samples were collected between February 8 and April 19 (black arrowheads).

showed a pattern corresponding to the dispersion of JCP, and were highest on March 15. Further, they were lower in the active group than in the placebo group at every time point. Significant difference in itchy skin score were observed on March 15 and April 5 (the end of sample intake), and a significant difference in total itchiness was observed on March 15.

As shown in Fig. 7, the percentage of the initial value of blood eosinophils in the active group was significantly lower on April $19(\mathrm{p}<0.05)$ and tended to be lower on April 5 compared with the placebo group $(\mathrm{p}=0.082)$. Significant between-group differences in serum $\operatorname{IgE}$ (total, specific for JCP, and specific for Japanese cypress 

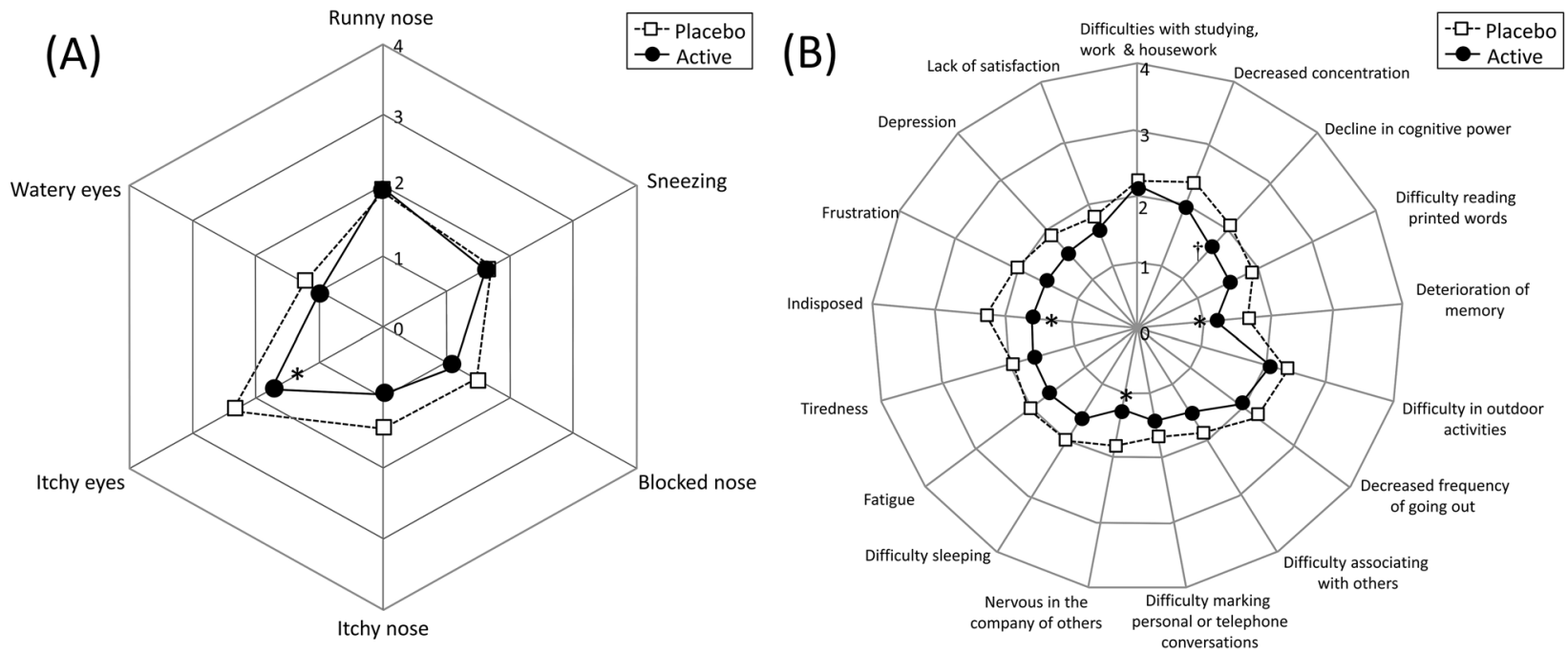

Fig. 5. Scores for nasal and eye symptoms (A) and quality of life (B) at 5 weeks after starting sample intake (on March 15). Values are expressed as mean scores of questionnaire items. ${ }^{*} \mathrm{p}<0.05 ; \uparrow \mathrm{p}<0.1$ versus the placebo group.

(A)

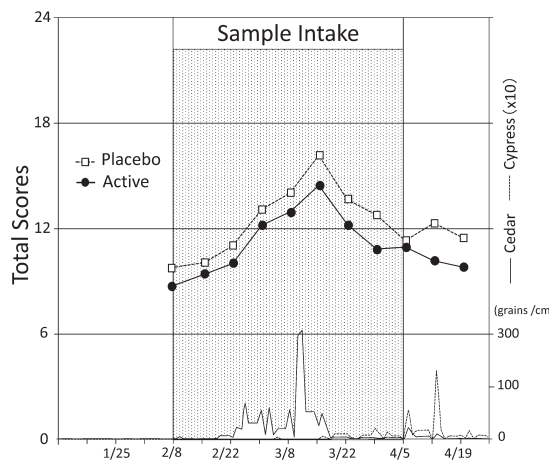

(B)

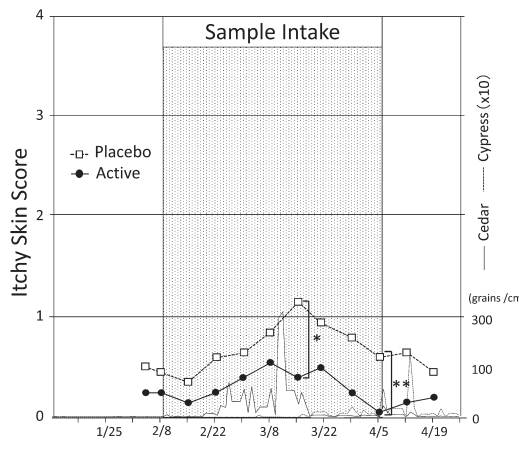

(C)

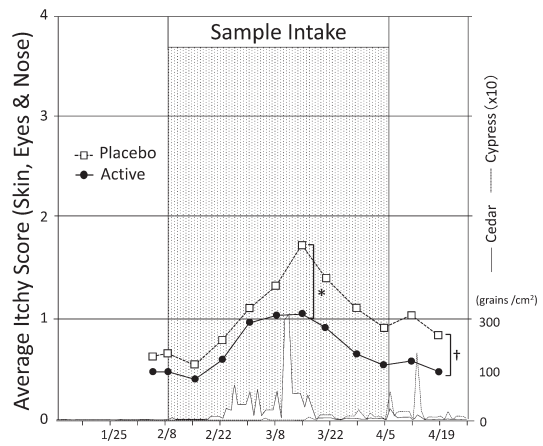

Fig. 6. Time-dependent changes in scores for pollinosis symptoms. (A) Total score, (B) itchy skin score, (C) average itchiness score (skin, eyes and nose). Values are expressed as mean scores of questionnaire items. ${ }^{*} \mathrm{p}<0.01 ;{ }^{*} \mathrm{p}<0.05 ; \dagger \mathrm{p}<0.1$ versus the placebo group. Squares, placebo group; circles, LP0132.

pollen) were not observed at any time point (data not shown).

In the clinical trial, compliance was almost $100 \%$, and there were no dropouts or side effects, such as diarrhea or abdominal pain. Also, there were no differences in the frequencies of drug use and hospital visits between the groups.

\section{DISCUSSION}

The aim of this study was to find LAB with antiallergy activity and to examine the effects of citrus juice fermented with the selected LAB on allergy symptoms of JCPsis. We demonstrated that most strains belonging

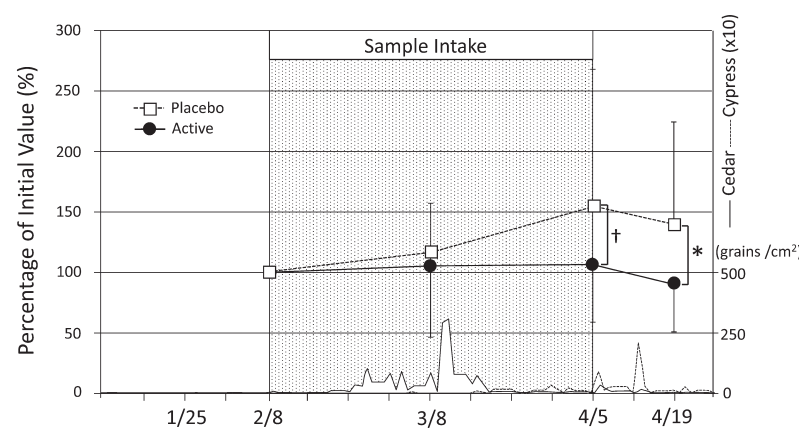

Fig. 7. Time-dependent changes in the proportion of blood eosinophils. Values are expressed as the mean \pm standard deviation. ${ }^{*} \mathrm{p}<0.05 ; \uparrow \mathrm{p}<0.1$ versus the placebo group. 
to $L$. plantarum could proliferate well in citrus juice with a $\mathrm{pH}$ of 3.5, whereas other species of LAB tested could not (Fig. 2). Since this $\mathrm{pH}$ is outside the range that general LAB can tolerate and proliferate in [19], the strains belonging to L. plantarum are thought to utilize special metabolic systems. One such system could be malolactic fermentation, a metabolic pathway for energy production that uses malic acid and plays an important role in wine production from acidic grape juice by $L$. plantarum and other LAB [20]. Malic acid was detected at a level of $0.03 \%$ in the citrus juice we used but not after fermentation (data not shown), suggesting that LP0132 utilized the malolactic fermentation pathway to proliferate in acidic citrus juice.

Previous studies have suggested that some strains of immunoregulatory probiotics that predominantly induce IL-10 can promote the development of regulatory $\mathrm{T}$ cells, thereby improving the symptoms of inflammatory diseases such as allergies, inflammatory bowel diseases and autoimmune diseases $[21,22]$. It has also been reported that LAB that induce a higher ratio of IL-10/IL12 production have a potent immunoregulatory potential [23]. For these reasons, we used IL-10-inducing activity and the ratio of IL-10/IL-12 as markers of anti-allergic potential. Following the secondary screening, LP0132 was selected as a strain with both high IL-10-inducing activity and a high ratio of IL-10/IL-12 in macrophages (Table 2).

The anti-allergy activity of the fermented citrus juice containing live LP0132 was demonstrated in the mouse model of JCPsis. For animals in the fermented juice group, nasal rubbing decreased to a level similar to that in the anti-histamine group (positive control), whereas the effect of unfermented citrus juice was lower (Fig. 3). Some kinds of citrus juice contain hesperidin, which reduces the inflammatory reaction, inhibits the degranulation of mast cells [13], relieves edema, and prevents anaphylaxis. Therefore, we posit that this weak anti-allergic activity in the unfermented juice group is probably due to the action of hesperidin. No significant difference was detected between the fermented and unfermented juice groups, but on average, the number of nasal rubbing events was $15 \%$ lower in the fermented juice group than in the unfermented juice group. Kim et al. [24] reported that hesperidin may act as a potential IL-5 antagonist and have a therapeutic effect on allergic asthma. However, there is less information available about the anti-allergy mechanism of hesperidin, and we have not yet examined the involvement of IL-5 in the anti-allergic mechanism of LP0132. So at this point, it is difficult to estimate if hesperidin and LP0132 exert anti- allergic effects through the same or different pathways. The reasons why a significant additive effect was not observed is unknown, but we think the large standard deviation in each group was one of the reasons.

Since the powder from heat-killed LP0132 cells was also effective in the animal experiment, it was considered that viable cells are not always necessary for anti-allergy effects. Therefore, we conducted a clinical trial using sterile fermented citrus juice containing heat-killed LP0132.

The clinical trial was conducted in 2010. In the spring of 2010, the amount of JCP dispersed in the participants' area of residence was lower than usual [25]. However, the symptomatic states of pollinosis and QOL were worsening in conjunction with the amount of JCP dispersed. Therefore, we consider that the clinical trial was conducted in a suitable setting for evaluating antipollinosis effects.

Our data demonstrate that the symptomatic states of pollinosis and impairments of QOL were alleviated in the active group as compared with the placebo group; that is, the average scores of itchy eyes, itchy skin (Fig. 5A), and some QOL questionnaire items were significantly attenuated (Fig. 5B).

It is interesting that, of the symptoms of pollinosis, the active drink particularly alleviated itching (of the nose, eyes, and skin) in this clinical trial (Fig. 6B, C), indicating that it may help to improve QOL. Itching is thought to occur via stimulation of C-fibers by mediators released from mast cells, including histamine and tryptase [26]. Based on the remarkable effect on itching observed in our trial, a possible effect of LP0132-fermented citrus juice on skin itchiness in atopic dermatitis is also suggested. Jang et al. reported that oral administration of L. plantarum PM008 isolated from kimchi (Korean pickles) reduced nasal rubbing induced by subcutaneous administration of histamine in mice [27]. This suggests that the L. plantarum strain may alleviate itching by affecting a mechanism other than histamine release. LP0132 may also effectively suppress the processes after degranulation of mast cells, since no significant decrease in serum levels of IgE (total, specific for Japanese cedar pollen, or specific for cypress pollen) was observed.

The percentage of blood eosinophils gradually increased during the later phase of the trial in the placebo group, but this increase was not observed in the active group. A significant difference in the percentage of the initial value of blood eosinophils between the placebo and active groups was observed at 3 weeks after the pollen peak (Fig. 7), whereas the improvement in clinical scores was observed immediately after the pollen peak. It 
is known that the ratio of eosinophils to total leukocytes increases after the onset of allergy, and so we speculate the difference between groups become more clear in the late stage due to accumulation of suppressive effects on the delayed reaction to JCPsis arising as a result of the continuous inhalation of antigen. Eosinophil cationic protein released during degranulation of eosinophils is closely associated with chronic inflammation or asthma [28]. Therefore, suppression of the level of eosinophils increase by LP0132-fermented citrus juice may also lead to benefits for individuals with other chronic allergies.

Although our animal experiment and clinical trial clearly showed that LP0132-fermented citrus juice improved the symptoms of JCPsis, the mechanism of action was not examined. Since the probiotic strain has a potent ability to induce IL-10, the immunoregulatory actions of IL-10, including downregulation of inflammatory responses and induction of Treg cells, might be responsible [29]. In a future study, we intend to clarify whether the fermented juice can promote IL-10 production and Treg cell development.

The present results show that it is not necessary for LP0132 to be alive to exert its anti-allergic activity, suggesting a mode of action other than the ecological competition of intestinal microbiota. This property provides advantages such as a long shelf life and reduced distribution costs of the product, which can be marketed as an anti-allergy drink. The fermented citrus juice also has some advantages with respect to the costs of manufacture and disposal compared with mixing raw citrus juice with heat-killed bacteria cultured separately. In conclusion, citrus juice fermented with the selected strain of L. plantarum, LP0132, showed anti-allergic potential. Continuous consumption of this juice may help in the relief of allergy symptoms and impaired QOL caused by JCPsis.

\section{ACKNOWLEDGEMENTS}

We thank all the volunteers who enrolled in the clinical trial. We also thank Drs. H. Kikuchi-Hayakawa and C. Kaga of Yakult Central Institute for Microbiological Research and Mr. D. Nozaki and Mrs. C. Nariai-Yoshioka of Yakult Honsha Co., Ltd., for technical support and helpful advice.

\section{REFERENCES}

1. Baba K, Nakae K. 2008. National epidemiological survey of nasal allergy 2008 (compared with 1998) in otolaryngologists and their family members. Prog Med (Tokyo) 28: 2001-2012 (in Japanese).

2. Strachan DP. 1989. Hay fever, hygiene, and household size. BMJ 299: 1259-1260. [Medline] [CrossRef]

3. Xiao JZ, Kondo S, Yanagisawa N, Takahashi N,
Odamaki T, Iwabuchi N, Miyaji K, Iwatsuki K, Togashi H, Enomoto K, Enomoto T. 2006. Probiotics in the treatment of Japanese cedar pollinosis: a doubleblind placebo-controlled trial. Clin Exp Allergy 36: 1425-1435. [Medline] [CrossRef]

4. Ishida Y, Nakamura F, Kanzato H, Sawada D, Yamamoto N, Kagata H, Oh-Ida M, Takeuchi H, Fujiwara S. 2005. Effect of milk fermented with Lactobacillus acidophilus strain L-92 on symptoms of Japanese cedar pollen allergy: a randomized placebo-controlled trial. Biosci Biotechnol Biochem 69: 1652-1660. [Medline] [CrossRef]

5. Kawase M, He F, Kubota A, Hiramatsu M, Saito H, Ishii T, Yasueda H, Akiyama K. 2009. Effect of fermented milk prepared with two probiotic strains on Japanese cedar pollinosis in a double-blind placebo-controlled clinical study. Int J Food Microbiol 128: 429-434. [Medline] [CrossRef]

6. Nagata Y, Yoshida M, Kitazawa H, Araki E, Gomyo T. 2010. Improvements in seasonal allergic disease with Lactobacillus plantarum No. 14. Biosci Biotechnol Biochem 74: 1869-1877. [Medline] [CrossRef]

7. Hasegawa T, Hirakawa $\mathrm{K}$, Matsumoto $\mathrm{T}$, Toki S, Maeyama Y, Morimatsu F. 2009. Efficacy of Lactobacillus plantarum strain HSK201 in relief from Japanese cedar pollinosis. Biosci Biotechnol Biochem 73: 2626-2631. [Medline] [CrossRef]

8. Yonekura S, Okamoto Y, Okawa T, Hisamitsu M, Chazono H, Kobayashi K, Sakurai D, Horiguchi S, Hanazawa T. 2009. Effects of daily intake of Lactobacillus paracasei strain KW3110 on Japanese cedar pollinosis. Allergy Asthma Proc 30: 397-405. [Medline] [CrossRef]

9. Tamura M, Shikina T, Morihana T, Hayama M, Kajimoto O, Sakamoto A, Kajimoto Y, Watanabe O, Nonaka C, Shida K, Nanno M. 2007. Effects of probiotics on allergic rhinitis induced by Japanese cedar pollen: randomized double-blind, placebocontrolled clinical trial. Int Arch Allergy Immunol 143: 75-82. [Medline] [CrossRef]

10. Nonaka $\mathrm{Y}$, Izumo $T$, Izumi $\mathrm{F}$, Maekawa $T$, Shibata H, Nakano A, Kishi A, Akatani K, Kiso Y. 2008. Antiallergic effects of Lactobacillus pentosus strain S-PT84 mediated by modulation of Th1/Th2 immunobalance and induction of IL-10 production. Int Arch Allergy Immunol 145: 249-257. [Medline] [CrossRef]

11. Emim JA, Oliveira AB, Lapa AJ. 1994. Pharmacological evaluation of the anti-inflammatory activity of a citrus bioflavonoid, hesperidin, and the isoflavonoids, duartin and claussequinone, in rats and mice. J Pharm Pharmacol 46: 118-122. [Medline] [CrossRef]

12. Wei D, Ci X, Chu X, Wei M, Hua S, Deng X. 2012. Hesperidin suppresses ovalbumin-induced airway inflammation in a mouse allergic asthma model. Inflammation 35: 114-121. [Medline] [CrossRef] 
13. Kobayashi S, Tanabe S. 2006. Evaluation of the antiallergic activity of Citrus unshiu using rat basophilic leukemia RBL-2H3 cells as well as basophils of patients with seasonal allergic rhinitis to pollen. Int $\mathrm{J}$ Mol Med 17: 511-515. [Medline]

14. Shida K, Kiyoshima-Shibata J, Nagaoka M, Watanabe K, Nanno M. 2006. Induction of interleukin-12 by Lactobacillus strains having a rigid cell wall resistant to intracellular digestion. J Dairy Sci 89: 3306-3317. [Medline] [CrossRef]

15. Kaji R, Kiyoshima-Shibata J, Nagaoka M, Nanno M, Shida K. 2010. Bacterial teichoic acids reverse predominant IL-12 production induced by certain lactobacillus strains into predominant IL-10 production via TLR2-dependent ERK activation in macrophages. J Immunol 184: 3505-3513. [Medline] [CrossRef]

16. Matsuki T, Watanabe K, Fujimoto J, Miyamoto Y, Takada T, Matsumoto K, Oyaizu H, Tanaka R. 2002. Development of $16 \mathrm{~S}$ rRNA-gene-targeted groupspecific primers for the detection and identification of predominant bacteria in human feces. Appl Environ Microbiol 68: 5445-5451. [Medline] [CrossRef]

17. Yamamoto K, Kawamura I, Tominaga T, Nomura T, Kohda C, Ito J, Mitsuyama M. 2005. Listeriolysin $\mathrm{O}$, a cytolysin derived from Listeria monocytogenes, inhibits generation of ovalbumin-specific Th2 immune response by skewing maturation of antigen-specific $\mathrm{T}$ cells into Th1 cells. Clin Exp Immunol 142: 268-274. [Medline] [CrossRef]

18. Okuda M, Okubo K, Gotoh M, Okamoto Y, Imano A, Baba K, Ogino T, Ishikawa K, Takenata Y, So N, Imai T, Enomoto M, Mandai T, Crawford B. 2003. [Standard questionnaire for QOL of Japanese patients with allergic rhinitis]. Arerugi 52 Suppl 1: 21-56 (in Japanese). [Medline]

19. Kandler O, Weiss N.1986. Regular, nonsporing grampositive rods. In Bergey's Manual of Systematic Bacteriology vol. 2, Sneath PHA, Mair NS, Sharpe ME, Holt JG (eds), The Williams \& Wilkins Co., Baltimore, pp 1208-1234.

20. Davis CR, Wibowo DJ, Lee TH, Fleet GH. 1986.
Growth and metabolism of lactic acid bacteria during and after malolactic fermentation of wines at different pH. Appl Environ Microbiol 51: 539-545. [Medline]

21. Yasui H, Shida K, Matsuzaki T, Yokokura T. 1999. Immunomodulatory function of lactic acid bacteria. Antonie van Leeuwenhoek 76: 383-389. [Medline] [CrossRef]

22. Shida K, Nanno M, Nagata S. 2011. Flexible cytokine production by macrophages and $\mathrm{T}$ cells in response to probiotic bacteria: a possible mechanism by which probiotics exert multifunctional immune regulatory activities. Gut Microbes 2: 109-114. [Medline] [CrossRef]

23. Foligne B, Nutten S, Grangette C, Dennin V, Goudercourt D, Poiret S, Dewulf J, Brassart D, Mercenier A, Pot B. 2007. Correlation between in vitro and in vivo immunomodulatory properties of lactic acid bacteria. World J Gastroenterol 13: 236-243. [Medline] [CrossRef]

24. Kim SH, Kim BK, Lee YC. 2011. Antiasthmatic effects of hesperidin, a potential Th2 cytokine antagonist, in a mouse model of allergic asthma. Mediators Inflamm 2011: 485402. [Medline] [CrossRef]

25. Tokyo Metropolitan Institute of Public HealthCedar and cypress pollen information for spring of 2010. Available at: http:/www.fukushihoken.metro.tokyo.jp/ kanho/kafun/H22/index.html (accessed 2010-05-30).

26. Ikoma A. 2013. Updated neurophysiology of itch. Biol Pharm Bull 36: 1235-1240. [Medline] [CrossRef]

27. Jang SE, Hyun YJ, Trinh HT, Han MJ, Kim DH. 2011. Anti-scratching behavioral effect of Lactobacillus plantarum PM008 isolated from kimchi in mice. Immunopharmacol Immunotoxicol 33: 539-544. [Medline] [CrossRef]

28. Bystrom J, Amin K, Bishop-Bailey D. 2011. Analysing the eosinophil cationic protein - a clue to the function of the eosinophil granulocyte. Respir Res 12: 10. [Medline] [CrossRef]

29. Pretolani M. 1999. Interleukin-10: an anti-inflammatory cytokine with therapeutic potential. Clin Exp Allergy 29: 1164-1171. [Medline] [CrossRef] 